\title{
Post-Traumatic Stress Symptoms in Healthcare Workers Dealing with the COVID-19 Pandemic: A Systematic Review
}

\author{
Gabriele d'Ettorre ${ }^{1}\left(\right.$, Giancarlo Ceccarelli ${ }^{2}{ }^{\oplus}$, Letizia Santinelli ${ }^{2}{ }^{\oplus}$, Paolo Vassalini ${ }^{2}$, Giuseppe Pietro Innocenti ${ }^{2}$, \\ Francesco Alessandri ${ }^{3}{ }^{(0)}$, Alexia E. Koukopoulos ${ }^{4}$, Alessandro Russo ${ }^{2}\left(\mathbb{D}\right.$, Gabriella d$^{\prime}$ Ettorre $^{2, *}{ }^{\circledR}$ and \\ Lorenzo Tarsitani ${ }^{4}[\mathbb{B}$ \\ 1 Department of Occupational Medicine, Local Health Authority of Lecce, 73100 Lecce, Italy; \\ gabriele.det@libero.it \\ 2 Department of Public Health and Infectious Diseases, Sapienza University of Rome, 00161 Rome, Italy; \\ giancarlo.ceccarelli@uniroma1.it (G.C.); letizia.santinelli@uniroma1.it (L.S.); \\ paolo.vassalini@uniroma1.it (P.V.); giuseppepietro.innocenti@uniroma1.it (G.P.I.); \\ alessandro.russo1982@gmail.com (A.R.) \\ 3 Department of Anesthesia and Intensive Care Medicine, Sapienza University of Rome, 00161 Rome, Italy; \\ francesco.alessandri@uniroma1.it \\ 4 Department of Human Neurosciences, Policlinico Umberto I, Sapienza University of Rome, 00161 Rome, Italy; \\ alexiakoukopoulos@gmail.com (A.E.K.); lorenzo.tarsitani@uniroma1.it (L.T.) \\ * Correspondence: gabriella.dettorre@uniroma1.it
}

Citation: d'Ettorre, G.; Ceccarelli, G.; Santinelli, L.; Vassalini, P.; Innocenti, G.P.; Alessandri, F.; Koukopoulos, A.E.; Russo, A.; d'Ettorre, G.; Tarsitani, L. Post-Traumatic Stress Symptoms in Healthcare Workers Dealing with the COVID-19 Pandemic: A Systematic Review. Int. J. Environ. Res. Public Health 2021, 18, 601. https://doi.org/10.3390/ ijerph18020601

Received: 21 November 2020 Accepted: 30 December 2020 Published: 12 January 2021

Publisher's Note: MDPI stays neutral with regard to jurisdictional clai$\mathrm{ms}$ in published maps and institutional affiliations.

Copyright: $(\odot 2021$ by the authors. Licensee MDPI, Basel, Switzerland. This article is an open access article distributed under the terms and conditions of the Creative Commons Attribution (CC BY) license (https:// creativecommons.org/licenses/by/ $4.0 /)$.

\begin{abstract}
Prevention of post-traumatic stress symptoms (PTSS) in healthcare workers (HCWs) facing the current COVID-19 pandemic is a challenge worldwide as HCWs are likely to experience acute and chronic, often unpredictable, occupational stressors leading to PTSS. This review aims to analyze the literature to discover which topics have been focused on and what the latest developments are in managing the occupational risk of PTSS in HCWs during the current pandemic. For the purpose of this review, we searched for publications in MEDLINE/Pubmed using selected keywords. The articles were reviewed and categorized into one or more of the following categories based on their subject matter: risk assessment, risk management, occurrence rates. A total of 16 publications matched our inclusion criteria. The topics discussed were: "Risk Assessment", “Occurrence Rates", and "Risk Management". Young age, low work experience, female gender, heavy workload, working in unsafe settings, and lack of training and social support were found to be predictors of PTSS. This review's findings showed the need for urgent interventions aimed at protecting HCWs from the psychological impact of traumatic events related to the pandemic and leading to PTSS; healthcare policies need to consider preventive and management strategies toward PTSS, and the related psychic sequelae, in HCWs.
\end{abstract}

Keywords: post-traumatic stress disorder; PTSD; COVID-19; healthcare worker; risk assessment; risk management

\section{Introduction}

Minimizing the psychological impact of the current coronavirus disease 2019 (COVID19) pandemic on healthcare workers (HCWs) represents a special challenge for healthcare systems through the world. In fact, HCWs represent the first-line fighters treating patients with COVID-19, and every day, they face a high risk of being infected and, consequently, of spreading the virus to other people [1-3]. HCWs are thus facing critical situations that increase their risk of suffering from the psychological impact of dealing with several unfavorable conditions, with consequences that might extend from psychological distress to mental health symptoms [4]. A body of evidence highlights that past infectious disease outbreaks, including the severe acute respiratory syndrome (SARS), the Middle East respiratory syndrome (MERS), and the 2009 novel influenza A (H1N1), were associated with mental health issues among HCWs [5,6], mostly post-traumatic stress symptoms 
(PTSS) and post-traumatic stress disorder (PTSD). In particular, research by Xiao et al. [7] revealed that HCWs working in settings exposed to a high risk of SARS were 2-3 times more likely to have high PTSS levels than those not exposed. Therefore, consistent with Dutheil et al. [8], the ongoing pandemic of COVID-19 is highly likely to also promote stress disorders in HCWs, potentially degenerating into chronic PTSD, as has already occurred in past outbreaks.

According to ICD-10, PTSD typically involves symptoms that can be classified into three groups: (1) intrusion-recurrent images, dreams or memories related to the traumatic experience; (2) avoidance-of places, people or topics related to the traumatic experience, accompanied by a general decrease in activity; (3) arousal-understood as increased psychophysiological reactivity in the form of attention-deficit disorders, circadian rhythm disorders, or increased vigilance [9]. In 2013, the DSM-5 [10] encoded important changes for what concerns post-traumatic stress conditions, particularly PTSD. In addition to changes in the symptomatologic diagnostic criteria, the current edition of the DSM better specified Criterion A about the trauma, eliminating the need of q person's response to the event involving intense fear, helplessness, or horror (criterion A2) and better clarifying the characteristics of the potentially traumatic experiences including, for the first time, a repeated or extreme indirect exposure to aversive details of the event(s), usually in the course of professional duties (criterion A4). Given the current concern with the COVID-19 pandemic, a summary of the evidence is required to allow policy makers to enact guidance for protecting HCWs. In urgent circumstances such as the ongoing pandemic, rapid reviews are recommended by the WHO [11]. We conducted a review of the literature on PTSS in HCWs employed in hospital settings during the COVID-19 pandemic. The aims of the critical revision were to evaluate the related (1) risk assessment, (2) risk management, and (3) occurrence rate.

\section{Materials and Methods}

\subsection{Search Strategy}

We conducted a systematic review of literature from February 2020 to 15 October 2020, regarding PTSS in HCWs employed in hospital settings. The general methods and selection criteria were based on different sources. First, two major scientific databases (MEDLINE/Pubmed) were used; second, the reference sections of the identified studies were scanned for additional relevant studies satisfying the criteria. Selected keywords were used to identify articles for this review of literature. The keywords were: "post-traumatic stress disorder", "PTSD", "post-traumatic stress symptoms", "PTSS", "COVID-19”, "SarsCoV-2", "healthcare worker", "hospital", "assessment", "management", "occurrence", and "prevalence". The keywords were systematically combined in order to conduct the literature search. For example, "PTSD" AND "healthcare 2orker" AND "hospital" was one combination. We aimed to identify original articles (i.e., non-reviews) using the abovementioned keywords with the following exclusion criteria: (1) not written in English; (2) studies focused on PTSS not related to the COVID-19 pandemic; and (3) qualitative studies.

\subsection{Data Extraction}

The screening of articles was carried out in two phases. In the first phase, articles were screened on the basis of title and abstract. The abstracts of all the selected titles were sorted for more detailed information. Two independent reviewers (G.d'E. and P.V.) read the abstracts and categorized them as relevant, not relevant, or possibly relevant. In the second phase, the full-text articles were assessed for eligibility. Two reviewers (G.d'E. and P.V.) independently applied inclusion and exclusion criteria to potentially eligible papers and both reviewers then independently extracted data from the original articles. Any disagreements were independently checked by a third reviewer (G.C.) and a consensus was reached. The Newcastle-Ottawa scale (NOS) for observational studies was used to evaluate the quality of the studies [12]. 


\subsection{Categorization of Selected Articles}

Every full-text article that met the inclusion criteria was reviewed and categorized into one or more of the following three categories based on its subject matter: risk assessment (articles aimed at the identification of occupational risk factors for PTSS), risk management (articles focused on occupational interventions for reducing the likelihood of PTSS occurrence), and occurrence rates (e.g., incidence or prevalence of PTSS among HCWs). This systematic review was reported in accordance with the Preferred Reporting Items for Systematic Reviews and Meta-Analyses (PRISMA) statement [13].

\section{Results}

The initial search retrieved 52 articles that matched our inclusion criteria. After reviewing the titles and abstracts, 35 articles were excluded. Therefore, 17 papers remained in the study (Figure 1). These 17 papers were then categorized according to their subject matter. The topics, discussed in order of frequency from highest to lowest, were risk assessment, occurrence rates, and risk management. All 17 papers assessed the risk of PTSS; 14 articles focused on occurrence rates, and 5 articles on risk management. In total, 3 papers targeted all three topics, 14 papers studied both risk assessment and occurrence rates, and 1 paper analyzed only risk assessment of PTSS (Table 1). Characteristics, outcomes, and main results of the selected studies are presented in Table 2.

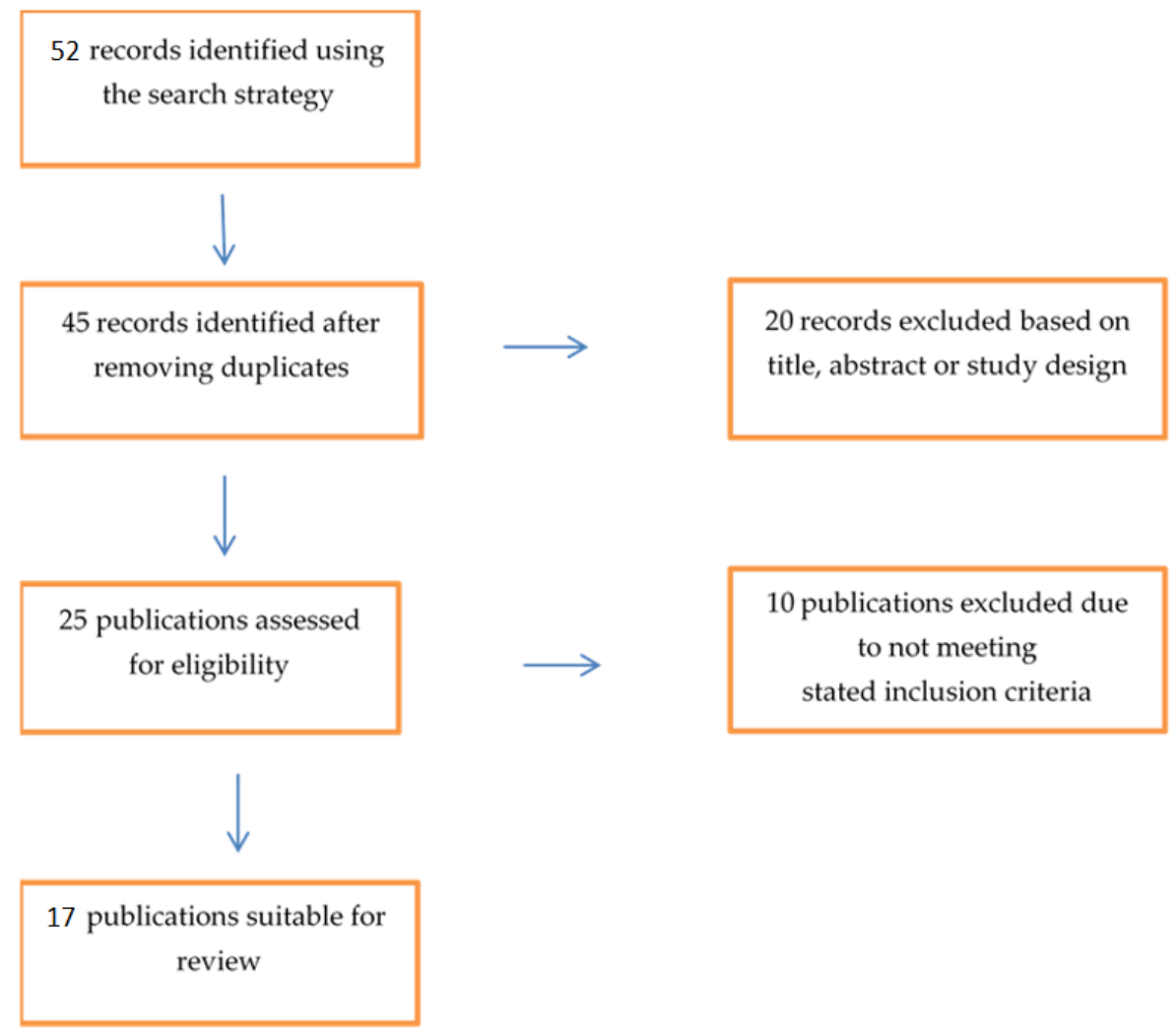

Figure 1. Study flow chart. The flow chart summarizes how the articles were reviewed and categorized based on risk assessment, risk management, and occurrence rates topics. 
Table 1. Summary of the studies included in the review.

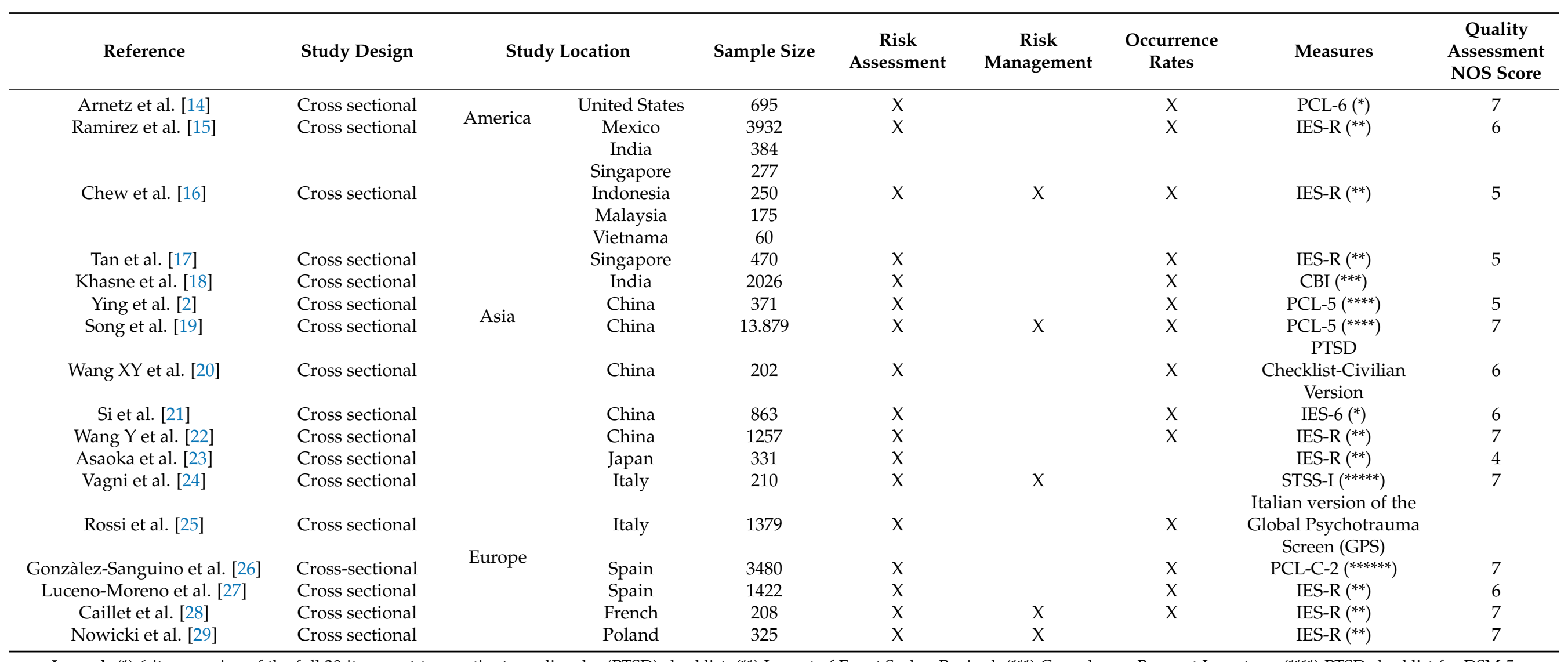

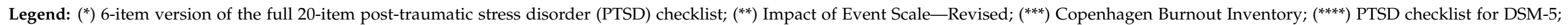
$(* * * *)$ Secondary Traumatic Stress Scale-Italian version; $(* * * * * *)$ civilian version of the Post-traumatic Stress Disorder Checklist-Reduced version 
Table 2. Characteristics, outcomes, and main results of the studies included in the review.

\begin{tabular}{|c|c|c|c|c|}
\hline Geo-Graphical area & Reference & Primary Outcome & $\begin{array}{l}\text { Methods/Investigation } \\
\text { Period/Setting }\end{array}$ & Occurrence Rate/Main Results/Risk Management \\
\hline \multirow{3}{*}{$\begin{array}{l}\text { North and Central } \\
\text { America }\end{array}$} & Arnetz et al. [14] & $\begin{array}{l}\text { To evaluate the association } \\
\text { between access to adequate } \\
\text { PPE and mental health } \\
\text { outcomes among U.S. nurses }\end{array}$ & $\begin{array}{l}\text { Online questionnaire/May } \\
\text { 2020/COVID-19: nurses }\end{array}$ & $\begin{array}{l}\text { - } \quad \text { symptoms of depression } 59.5 \% \text { (severe depression } 9.7 \% \text { ) } \\
\text { - } \quad \text { anxiety } 54.9 \% \text { (severe anxiety } 8.3 \% \text { ) } \\
\text { symptoms of PTSD } 29.1 \% \\
\text { Subjects lacking access to adequate PPE reported a higher impact of } \\
\text { symptoms of depression, anxiety, and post-traumatic stress disorder }\end{array}$ \\
\hline & & & & $\begin{array}{l}\text { - } \quad \text { Post-traumatic stress } 27.7 \% \\
\text { - } \quad \text { Psychological distress: }\end{array}$ \\
\hline & Ramirez et al. [15] & $\begin{array}{l}\text { To evaluate the presence of } \\
\text { psychological distress, signs } \\
\text { of post-traumatic stress, and } \\
\text { to identify the groups of } \\
\text { subjects at highest risk }\end{array}$ & $\begin{array}{l}\text { Online survey/March-April } \\
\text { 2020/COVID-19: } \\
\text { volunteers, mainly students } \\
\text { and employees of a Mexican } \\
\text { University, HCWs and their } \\
\text { contacts }\end{array}$ & $\begin{array}{l}\text { intrusive thoughts } 22 \% \\
\text { avoidance } 22.3 \% \\
\text { hyperarousal } 12.2 \% \\
\text { Younger ages, female sex, employed status, single condition, socially } \\
\text { isolating, more days in isolation, a perception of a high risk of contracting } \\
\text { COVID-19, a change in routine, less activity and having been economically } \\
\text { impacted were variables positively correlated with higher } \\
\text { psychological distress. } \\
\text { Ranges in analyzed countries: }\end{array}$ \\
\hline \multirow[t]{2}{*}{ South-East Asia } & \multirow[t]{2}{*}{ Chew et al. [16] } & \multirow[t]{2}{*}{$\begin{array}{l}\text { To compare the } \\
\text { psychological outcomes } \\
\text { during the COVID-19 } \\
\text { pandemic and identify } \\
\text { factors associated with } \\
\text { adverse psychological } \\
\text { outcomes }\end{array}$} & $\begin{array}{l}\text { Self-administered } \\
\text { survey/April-June } \\
\text { 2020/COVID-19: HCWs }\end{array}$ & $\begin{array}{l}\text { - } \quad \text { Depression from } 0,8 \% \text { to } 14,3 \% \\
\text { - } \quad \text { Anxiety from } 0,8 \% \text { to } 6,7 \% \\
\text { - } \quad \text { Stress from } 3,3 \% \text { to } 6,8 \% \\
\text { - } \quad \text { PTSD from } 2,1 \% \text { to } 15 \% \\
\text { Non-medically trained personnel, the presence of physical symptoms, and } \\
\text { presence of prior medical conditions were independent predictors of adverse } \\
\text { psychological outcome. } \\
\text { Resources proposed to reduce PTSS: }\end{array}$ \\
\hline & & & & $\begin{array}{l}\text { - Improving accessibility to early psychological support (in the form of coun- } \\
\text { selling, internet-based cognitive-behavioral therapy) } \\
\text { * Passive psychoeducation (educational pamphlets, emails or website) }\end{array}$ \\
\hline
\end{tabular}


Table 2. Cont.

\begin{tabular}{|c|c|c|c|c|}
\hline Geo-Graphical area & Reference & Primary Outcome & $\begin{array}{l}\text { Methods/Investigation } \\
\text { Period/Setting }\end{array}$ & Occurrence Rate/Main Results/Risk Management \\
\hline & Tan et al. [17] & $\begin{array}{l}\text { To examine the } \\
\text { psychological distress, } \\
\text { depression, anxiety, and } \\
\text { stress experienced by } \\
\text { healthcare workers }\end{array}$ & $\begin{array}{l}\text { Self-administered } \\
\text { survey/February-March } \\
\text { 2020/COVID-19: HCWs }\end{array}$ & $\begin{array}{l}\text { - } \quad \text { anxiety } 14.5 \% \\
\text { - } \quad \text { sepression } 8.9 \% \\
\text { - } \quad \text { clinical concern of PTSD } 7.7 \% \\
\text { The prevalence of anxiety was higher among non-medical healthcare } \\
\text { workers than medical personnel. Non-medical HCWs are at highest risk for } \\
\text { psychological distress. }\end{array}$ \\
\hline & Khasne et al. [18] & $\begin{array}{l}\text { To evaluate the prevalence of } \\
\text { burnout in HCWs involved } \\
\text { in the care of COVID-19 } \\
\text { patients }\end{array}$ & $\begin{array}{l}\text { Questionnaire-based } \\
\text { survey/date not } \\
\text { reported/COVID-19: HCWs }\end{array}$ & $\begin{array}{l}\text { - } \quad \text { personal burnout } 44.6 \% \\
\text { work-related burn-out } 26.9 \% \text { pandemic-related burnout } 52.8 \% \\
\text { Pandemic-related burnout was } 1.67 \text { times more frequent in medical doctors } \\
\text { and } 5 \text { times in support staff. The prevalence of personal and work-related } \\
\text { burnout was significantly higher among younger respondents and females. }\end{array}$ \\
\hline & Ying et al. [2] & $\begin{array}{l}\text { To investigate the mental } \\
\text { health status and related } \\
\text { factors in families of HCWs } \\
\text { employed in hospital }\end{array}$ & $\begin{array}{l}\text { Online self-administered } \\
\text { questionnaires/February } \\
\text { 2020/COVID-19: families of } \\
\text { HCWs }\end{array}$ & $\begin{array}{l}\text { - anxiety } 33.73 \% \\
\text { depression symptoms } 29.35 \% \\
\text { Risk factors for depressive symptoms were more time spent thinking about } \\
\text { COVID-19, longer average working time per week worked by family } \\
\text { members (that is, HCWs), and being parents and other next of kin of HCWs. }\end{array}$ \\
\hline & \multirow{3}{*}{ Song et al. [19] } & \multirow{3}{*}{$\begin{array}{l}\text { To assess the mental health } \\
\text { of emergency department } \\
\text { medical staff during the } \\
\text { SARS-CoV-2 epidemic }\end{array}$} & \multirow{3}{*}{$\begin{array}{l}\text { Electronic } \\
\text { questionnaires/February- } \\
\text { March 2020/COVID-19: } \\
\text { HCWs }\end{array}$} & $\begin{array}{l}\text { - } \quad \text { Depressive symptoms } 25.2 \% \\
\text { PTSD } 9.1 \%\end{array}$ \\
\hline & & & & $\begin{array}{c}\text { A higher risk of developing depressive symptoms and PTSD was present in } \\
\text { HCWs who were middle-aged, who had worked for fewer years, had longer } \\
\text { daily work time, and had lower levels of social support. Being a man was } \\
\text { associated with a higher probability of depressive symptoms and PTSD. } \\
\text { Nurses had a higher risk of PTSD than doctors. } \\
\text { Resources proposed to reduce PTSS: }\end{array}$ \\
\hline & & & & $\begin{array}{l}\text { Psychological skills training to better regulate the psychological status of } \\
\text { medical staff and to mitigate the psychological problems } \\
\text { Targeted psychological interventions to promote the mental health of medi- } \\
\text { cal staff }\end{array}$ \\
\hline
\end{tabular}


Table 2. Cont.

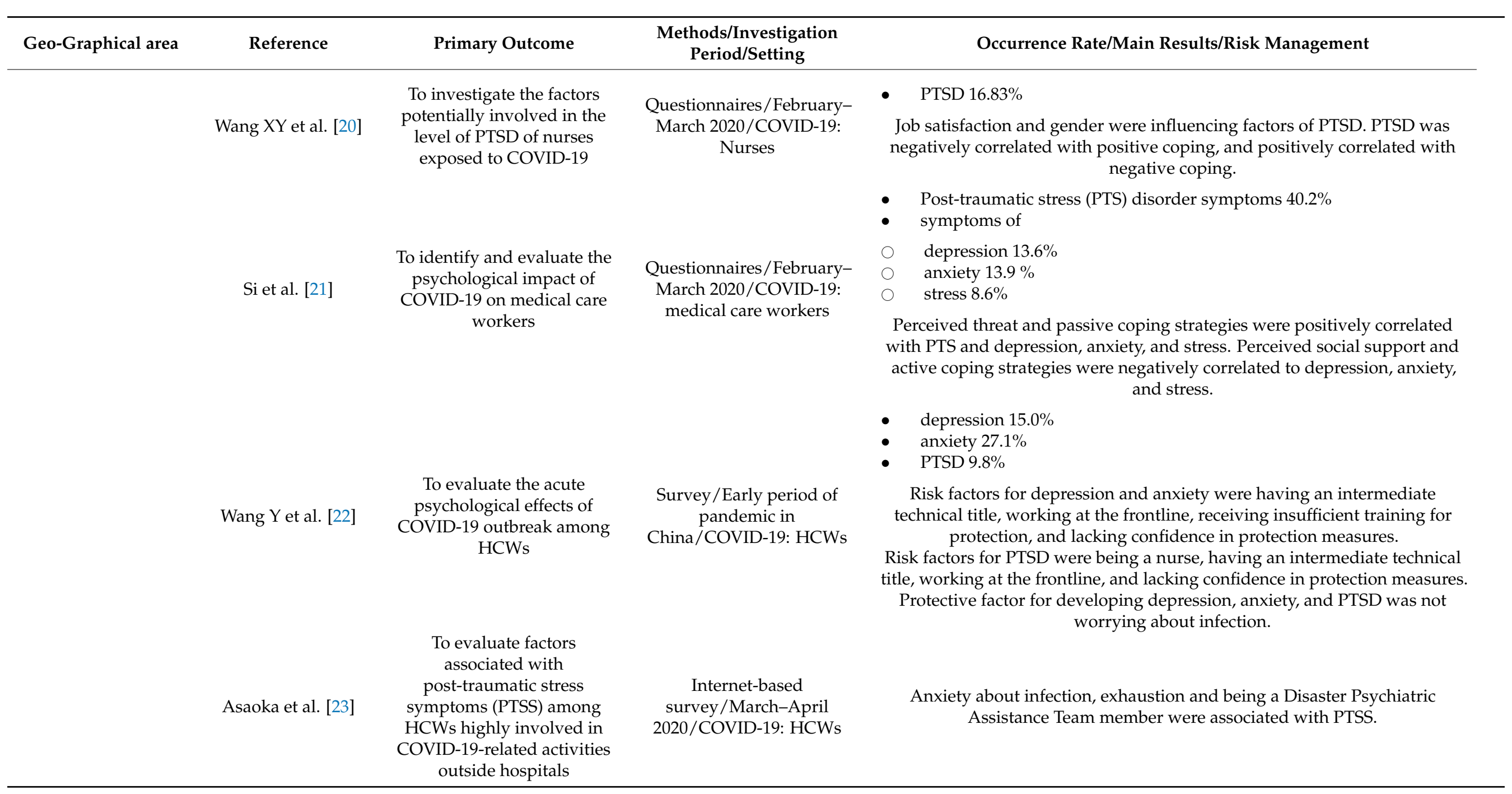


Table 2. Cont.

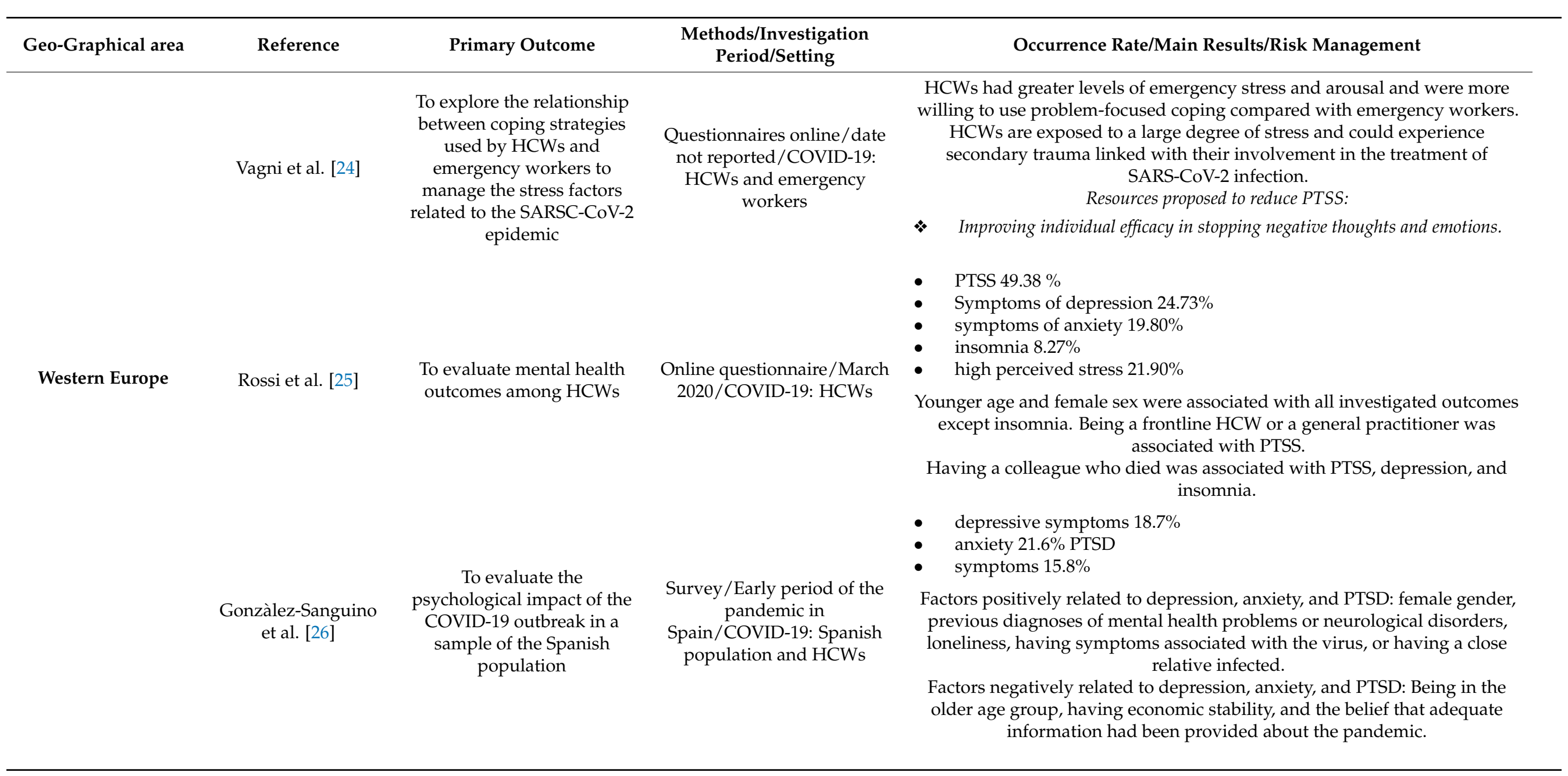


Table 2. Cont.

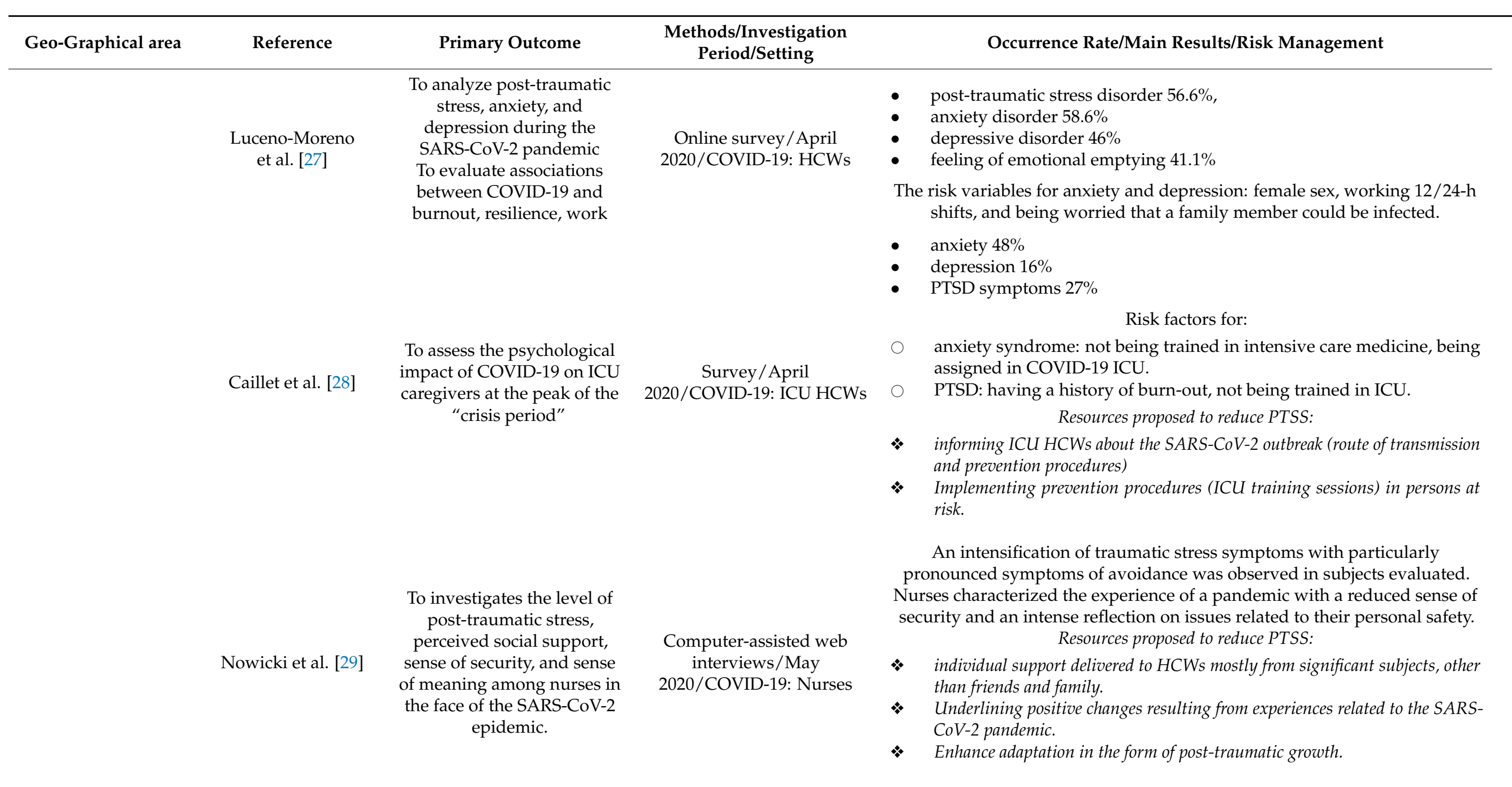




\section{Discussion}

During the current COVID-19 pandemic, HCWs face unprecedented scenarios often outside their ordinary levels of experience and training, as they are at the forefront of the fight against the virus worldwide. This critical situation increases HCWs' risk of suffering from symptoms ranging from psychological distress to psychiatric disorders, as a result of the effort to continuously fight with several COVID-related unfavorable conditions [4]. To better clarify the characteristics of the pandemic-related traumatic experiences, we conducted a review of literature on PTSS in HCWs employed in hospital settings during the COVID-19 pandemic, focusing on risk assessment, risk management, and occurrence rates.

\subsection{Risk Assessment of Work-Related PTSS}

The 17 articles focusing on the risk assessment of work-related PTSS among hospital HCWs during the COVID-19 pandemic aimed to identify the risk profile for HCWs with regard to organizational and individual factors making HCWs susceptible to PTSS. In particular, 11 papers analyzed the pre-trauma risk factors and detected predictors of PTSS at individual level, 5 articles focused on post-traumatic risk factors of PTSS at both organizational and individual level, and 3 papers focused on both the pre- and posttraumatic risk factors. Regarding the individual pre-trauma risk factors, female gender, young age, low work experience, not living with a partner, and lack of training were found to be related to a high risk of PTSS. Most of the selected articles showed female gender at a higher risk than male, consistent with existing studies on PTSS in the general population and in HCWs before the COVID-19 outbreak [30,31]; given this gender susceptibility to PTSS, Gonzalez-Sanguino et al. [26] hypothesized that during the current pandemic, women tend to take on a caregiving role at home and, because of the need to balance this with healthcare work, are consequently at increased risk and more vulnerable in this situation of overload. By contrast, Song et al. [19], in a cross-sectional study conducted in China, found increased occurrence of PTSS in male medical staff compared to female and concluded that this difference may be due to the timing of their study, which was conducted later than the comparative studies, when the psychological impact of stressors may have been minimized and the mental status of female medical staff may have gradually improved over time. Moreover, women tend to pay gradually more attention to their experiences and feelings and are more willing to express their emotions; this behavior leads to the selfregulation of emotions and, therefore, may defuse the impact of stressors over time [16,32]. A convergence was found on the increased risk of PTSS in medical staff who are unmarried, divorced, or widowed; based on this finding, Song et al. [19] speculated that such HCWs receive less care and/or communication from their partner and may experience less family support, as highlighted by other studies that showed increased risk of PTSS in workers lacking social support.

Interestingly, a relationship was found between lack of medical training on COVID-19 and occurrence of PTSS; in fact, increased rates of PTSS were found among untrained HCWs than among trained ones; in particular, a multicentric study performed by Chew et al. [16] found that non-medically trained HCWs were at higher risk of adverse psychological outcomes, including PTSS, compared to their medically trained counterparts. This is in agreement with a recent study on HCWs during the start of the pandemic in Singapore [17], as well as a recent study in China [16] that surprisingly demonstrated that frontline nurses had significantly decreased vicarious traumatization scores in comparison with non-frontline nurses during the COVID-19 pandemic; moreover, a relationship was found between the lack of accessibility to first-hand medical information on the pandemic, less formal training and confidence in infectious control measures, and increased occurrence of traumatization in non-frontline and non-trained nurses compared to frontline and trained nurses [17].

Younger age was found to be a risk factor for anxiety and PTSS, in accordance with data regarding workers different from HCWs; in particular, past studies found that in the general population, older adults have better mental health than younger adults [33,34], and 
this seems to hold true during the current pandemic [14]. It is also possible that older HCWs are more experienced and better equipped both professionally and psychologically to deal with the stress of the pandemic. Consistent with this hypothesis, an Italian report [35] aimed at the organizational changes and management challenges presented by the pandemic found that the difficulties in patient care were likely greatest for the newer, lesser-skilled nurses. These results lead us to conclude that nurse managers should increase training and support related to COVID-19 care for younger, less experienced nurses in order to mitigate mental health problems, including PTSS [14].

Post-traumatic risk factors of PTSS were found as follows: low social support at work, heavy workload, working in unsafe settings (e.g., lack of personal protective equipment), passive coping, anxiety, and burnout. Considering that the healthcare system has operated under the most challenging conditions during the period of pandemic, the related emotional and physical exhaustion in HCWs represents a major concern. Work-related consequences of this condition, called burnout, include poorer quality of care, professional mistakes, probably reduced attention to individual protection procedures, and increased risk of contagion in the workplace [36]. The impacts of burnout on the safety of HCWs and patients highlight the need for early identification of this health condition in the work environment and preventive interventions. In particular, management should be proactive in and supportive of improving working conditions to avoid burnout risks: implementation of training and technical updates on COVID-19 for HCWs, adequate supply of personal protective equipment (PPE), ban of prolonged working hours, and availability of counseling services have been proposed as possible responses $[18,36]$.

This present review found strong concordance regarding the negative relationship between social support and PTSS. According to the literature, lack of social support is a known predictor of occupational stress in HCWs $[37,38]$, and it is defined as "the feeling that one is cared for and has assistance available from other people" and "that one is part of a supportive social network" [38]. As revealed by Si et al. [21], a supportive work environment is a buffering factor of negative psychological health among HCWs and protects them from PTSS during the COVID-19 pandemic; in fact, in their study, the authors found that social support had the greatest impact on the mental health of HCWs: low (OR: 5.49, 95\% CI: 4.04, 7.45) and moderate (OR: 2.73, 95\% CI: 2.42, 3.07) levels of social support were associated with a higher risk of PTSD compared to high levels of social support [19].

During the first wave of COVID-19, the lack of personal protective equipment (PPE) was identified as a top concern for HCWs throughout the world, and results of the current review indicate that this was a significant factor impacting HCWs' mental health; in fact, in a cross-sectional study, Arnetz et al. [14] found a reverse dose-response relationship between lack of PPE provision and PTSS scores: the severity of PTSS was significantly lower as PPE provision frequency increased (PTSS scores decreased from 14.0 (9.0-18.0) to 9.0 (7.0-13.0), $p<0.001)$; moreover, working in potentially lethal settings but lacking PPE was found to be a worse factor impacting the mental health of HCWs and leading to depression and anxiety other than PTSS. Actually, PPI shortages are still a real problem for many health professionals, especially in areas with less prosperous economies or poor health services. The availability of effective barrier devices whose quality inspires trust is crucial to reduce the perception of danger of HCVs in the setting of transmissible diseases. In fact, even more than preventive behaviors, barrier devices are perceived as an extension of the body's ability to defend itself against external aggression, a sort of shield or armor able to physically stop the virus; in this sense, their continued availability is essential to fueling the resilience of HCWs [39].

\subsection{Risk Management of PTSS}

The articles focused on risk management showed the ways to moderate the occurrence of PTSS through HCWs' occupational training and the improvement of social support at work. Convergence was found about the need of occupational training targeted at pandemic and infectious control measures. Interestingly, Chew et al. [16] observed that passive 
training through educational pamphlets, emails, or websites was effective in minimizing PTSS in HCWs experiencing psychological distress. In particular, education on the natural history of the virus and the appropriate use of infection control measures, especially for non-medically trained HCWs, was a predictor of lower risk of PTSS compared to that for non-trained HCWs who received no such education. Moreover, brief passive psychoeducational interventions targeting high-risk groups were shown to be effective during the peak of the pandemic, although to date, the extent of their benefit remains unknown. Consistent with these studies, Caillet et al. [28] showed lack of medical training as an independent factor for PTSS in HCWs employed in COVID-19-intensive care units (OR = 2.155 (95\% $\mathrm{CI}, 1.047-4.440), p=0.04)$; given this finding, the authors suggested the need for training and re-training HCWs continuously exposed to the risk of both acquiring the disease and spreading SARS-CoV-2 to their family, friends, and colleagues. Regarding the protective role of training, interesting research was conducted by Tan et al. [17] evaluating, among others, traumatic stress among medical workers (doctors and nurses) and non-medical workers (caregivers, pharmacists, technicians. administration, office workers, and cleaners) in Singapore. The authors observed a lower mean PTSS score among HCWs during the COVID-19 pandemic than during the SARS epidemic, when the severity of PTSS was three times higher than in the current pandemic. These findings led the authors to infer that respondents were more prepared for the COVID-19 pandemic, and they implemented infection control procedures following experiences from the previous SARS epidemic.

A body of evidence has shown that training should also be targeted at improving a supportive work environment. Therefore, according to existing literature, hospital management and supervisors need to anticipate the effects of traumatic exposure by training HCWs in evidence-based anticipatory methods of coping with stressful events, in reducing the development of post-traumatic stress reactions and general distress, and in educating HCWs to support their colleagues after adverse events [40]. A study by Zhang et al. [3] showed that simple standardized questionnaires can be used, which should be supplemented with a brief questionnaire assessing work conditions (demands, decision latitude, and support). A description of a protective program has been published by Cao et al. [41] based upon hands-on recent experience in China. An important part of that program was the repeated use of a short questionnaire supplemented with personal interviews with a representative group of employees.

Moreover, according to Theorell [42], a supportive leadership should implement the following measures to minimize the impact of stressors on the psychological status of HCWs dealing with the current pandemic: (1) flexible work schedules that are adapted to the ever-changing situation; (2) sleep hygiene, which is facilitated by wise shift cycles and good possibilities for undisturbed sleep; (3) social support to family members; worries for family members could add to the caregiver's health deterioration; (4) participation in decision making; (5) facilitation of good coping mechanisms; (6) facilitation of cultural experiences, for instance, easy electronic access to films, concerts, and lectures during leisure time. Supervisors should also be involved in monitoring the health of their staff. Finally, with regard to the coping strategies adopted by HCWs to minimize their stress levels, Vagni et al. [24], in a cross-sectional study, showed that blocking negative or unpleasant emotions and thoughts reduced the arousal and intrusion levels of the trauma during the emergency phase of the pandemic, unlike problem-focused strategies. Based on this finding, the authors hypothesized that HCWs, during the ongoing COVID-19 pandemic, frequently incur a lack of a cognitive process of emotions, thus failing to identify their emotional reactions, which tends to be associated with maladaptive behaviors leading to increased risk of PTSS. Moreover, problem-focused coping strategies were not found to be effective in protecting HCWs in the first wave of the pandemic, probably due to a lack of scientific knowledge about therapeutic and treatment procedures effective for COVID-19. 


\subsection{Occurrence of PTSS}

The 14 selected articles analyzing the occurrence of PTSS in HCWs dealing with the COVID-19 pandemic showed a range between $2.1 \%$ and $73.4 \%$. This wide range is attributable to (1) the different timing of the studies and (2) the healthcare settings investigated. In particular, Song et al. [19], in a study conducted from 28 February 2020 to 18 March 2020, when the outbreak in China had been controlled and the work pressure of the HCWs was significantly reduced compared to the peak period of the outbreak, found lower prevalence rates of PTSS (9.1\%) compared to studies conducted during the peak period of COVID-19 in China [43]. In line with this finding, the study by Rossi et al. [25], performed in Italy between 27 and 31 March, during the peak of the outbreak in Italy, showed a higher occurrence of HCWs being affected by PTSS, compared to studies conducted later, when the pandemic was controlled. Regarding healthcare settings, increased rates of PTSS were found in inpatient settings (up to 70\%), particularly among HCWs caring for COVID-19 patients or employed in emergency hospital wards [14].

\subsection{A Call for Action}

The findings of the present review show the need for urgent interventions aiming to protect HCWs from the psychological impact of traumatic events related to the pandemic and leading to PTSS. A body of evidence has been found about the following predictors of increased risk of suffering from PTSS: young age, female gender, not being a graduate, heavy workload, low medical training, not living with a partner, and low social support. Therefore, healthcare organizations should focus on the supportive resources available for HCWs in order to prevent the heavy psychological impairment related to PTSS in HCWs dealing with the COVID-19 outbreak. In fact, PTSS involve chronic severe anxiety with re-experiencing of the traumatic event, flashbacks, nightmares, increased arousal, and reduced social life and could lead to PTSD. As people suffering from PTSD are more at risk of suicidal ideation, suicide attempts, and death by suicide in huge proportions (2-5 times) [44], the prevention of PTSD is a special concern for HCWs, considering that they are already in occupations which are at increased risk [45], and people suffering from PTSS are prone to not seeking care because of barriers such as lack of information, being afraid of stigmatization, or the belief that symptoms may decrease with time [46]. Presently, a special effort is required to prevent PTSD as a secondary effect of the SARS-Cov2 pandemic among HCWs facing COVID-19 patients. Therefore, healthcare policies need to take into account preventive and management strategies toward PTSS, and the related psychic sequelae, as soon as possible, including policies to implement regular screening of PTSS in HCWs. There is also a need for urgent intervention to identify and treat HCWs with PTSD, as such an approach can reduce the risk of chronic psychological impairment.

\section{Limits of the Study}

There were several limitations in this review. Firstly, because of the use of the inclusion criteria, we could have missed potentially relevant papers in the first step of data selection. Secondly, the cross-sectional profile of all the selected studies limits the possibility of drawing strong conclusions; therefore, caution should be taken in generalizing the findings. Moreover, the findings could have been influenced by organizational factors intrinsic to the local occupational context of each study and, consequently, not be true for all healthcare workers: in particular, the different (a) geographical contexts, (b) cultural variables, and (c) chronological periods of the COVID-19 pandemic in which the aforementioned studies were carried out may have influenced the different types of psychological responses to the same stressor among HCWs. Interestingly, the totality of the selected works was produced mainly in South East Asia and China and in Western Europe, and only two in the United States and Mexico. This evidence can obviously constitute a bias and somehow orient the reading of the topic on the basis of specific cultural backgrounds. Finally, the wide range of occurrence rates observed is attributable to different (1) healthcare settings investigated and 
(2) timing of the studies; for this reason, a direct comparison between the data provided by the different studies is not always possible and can in some cases be misleading.

\section{Conclusions}

The SARS-CoV2 pandemic represented a challenge at multiple levels: for the management of public health, for the discovery of new therapeutic and vaccine resources, for the understanding of etiology and pathogenesis [47-52]. However, it also posed a great challenge for healthcare workers forced to measure themselves against a disease that was risky for their own health as well as that of their patients. This systematic review of the literature showed young age, low work experience, female gender, heavy workload, working in unsafe settings, and lack of training and social support as predictors of PTSS. Moreover, the need for urgent interventions aimed at protecting HCWs from the psychological impact of traumatic events related to the pandemic and leading to PTSS is increasingly a key issue in the management of COVID-19 pandemic. Finally, there is an urgent need to define new healthcare policies devoted to preventive and management strategies toward PTSS, and the related psychic sequelae, in HCWs.

Author Contributions: Conceptualization, G.d. (Gabriele d'Ettorre), G.C., G.d. (Gabriella d'Ettorre), and L.T.; methodology, G.C., P.V., and G.d. (Gabriele d'Ettorre); software, G.d. (Gabriele d'Ettorre); validation, G.C. and G.d. (Gabriele d'Ettorre); formal analysis, G.d.(Gabriele d'Ettorre), P.V., and A.R.; investigation, G.d. (Gabriele d'Ettorre), G.C., and G.d. (Gabriella d'Ettorre), L.T; resources, G.P.I., A.E.K., F.A., L.S., and P.V.; data curation, G.d. (Gabriele d'Ettorre), G.C., P.V., A.R., G.d. (Gabriella d'Ettorre), L.T., G.P.I., A.E.K., and F.A.; writing—original draft preparation, G.d. (Gabriele d'Ettorre), G.C., and G.d. (Gabriella d'Ettorre); writing - review and editing, L.S., V.P, and A.R.; visualization, G.d. (Gabriele d'Ettorre), G.C., G.d. (Gabriella d'Ettorre), and L.T.; supervision, G.d. (Gabriella d'Ettorre) and L.T.; project administration, G.d. (Gabriele d'Ettorre) and L.T. All authors have read and agreed to the published version of the manuscript.

Funding: This research was funded by Sapienza, University of Rome.

Conflicts of Interest: The authors declare no conflict of interest.

\section{References}

1. Garzaro, G.; Clari, M.; Ciocan, C.; Grillo, E.; Mansour, I.; Godono, A.; Borgna, L.G.; Sciannameo, V.; Costa, G.; Raciti, I.M.; et al. COVID-19 infection and diffusion among the healthcare workforce in a large university-hospital in northwest Italy. Med. Lav. 2020, 111, 184-189. [CrossRef] [PubMed]

2. Ying, Y.; Ruan, L.; Kong, F.; Zhu, B.; Ji, Y.; Lou, Z. Mental health status among family members of health care workers in Ningbo, China, during the coronavirus disease 2019 (COVID-19) outbreak: A cross-sectional study. BMC Psychiatry 2020, 20, 1-10. [CrossRef] [PubMed]

3. Zhang, W.R.; Wang, K.; Yin, L.; Zhao, W.F.; Xue, Q.; Peng, M.; Min, B.Q.; Tian, Q.; Leng, H.X.; Du, J.L.; et al. Mental health and psychosocial problems of medical health workers during the COVID-19 epidemic in China. Psychother. Psychosom. 2020, 89, 242-250. [CrossRef]

4. Carmassi, C.; Cerveri, G.; Bui, E.; Gesi, C.; Dell'Osso, L. Defining Effective Strategies to Prevent Post-Traumatic Stress in Healthcare Emergency Workers Facing the COVID-19 Pandemic in Italy. CNS Spectr. 2020, 25, 293-294. [CrossRef]

5. Bai, Y.; Lin, C.C.; Lin, C.Y.; Chen, J.Y.; Chue, C.M.; Chou, P. Survey of stress reactions among health care workers involved with the SARS outbreak. Psychiatr. Serv. 2004, 55, 1055-1057. [CrossRef]

6. Lee, S.M.; Kang, W.S.; Cho, A.R.; Kim, T.; Park, J.K. Psychological impact of the 2015 MERS outbreak on hospital workers and quarantined hemodialysis patients. Compr. Psychiatry 2018, 87, 123-127. [CrossRef]

7. Xiao, X.; Zhu, X.; Fu, S.; Hu, Y.; Li, X.; Xiao, J. Psychological impact of healthcare workers in China during COVID-19 pneumonia epidemic: A multi-center cross-sectional survey investigation. J. Affect. Disord. 2020, 274, 405-410. [CrossRef]

8. Dutheil, F.; Mondillon, L.; Navel, V. PTSD as the second tsunami of the SARS-Cov-2 pandemic. Psychol. Med. 2020, 33, 1-2. [CrossRef]

9. Peters, L.; Slade, T.; Andrews, G. A comparison of ICD10 and DSM-IV criteria for posttraumatic stress disorder. J. Trauma Stress. 1999, 12, 335-343. [CrossRef]

10. American Pyschiatric Association. Sleep-Wake Disorders. Available online: http://www.dsm5.org/ (accessed on 10 November 2020).

11. WHO. Rapid Reviews to Strengthen Health Policy and Systems: A Practical Guide. 2017. Available online: https:/ /www.who. int/alliance-hpsr/resources/publications/rapid-review-guide/en/ (accessed on 10 November 2020). 
12. Wells, G.; Shea, B.; O'Connell, D.; Peterson, J.; Welch, V.; Losos, M.; Tugwell, P. The Newcastle-Ottawa Scale (NOS) for Assessing the Quality of Nonrandomised Studies in Meta-Analyses. Available online: http://www.ohri.ca/programs/clinical_ epidemiology/oxford.asp (accessed on 15 October 2020).

13. Moher, D. Preferred Reporting Items for Systematic Reviews and Meta-Analyses: The PRISMA Statement. Ann. Intern. Med. 2009, 151, 264. [CrossRef]

14. Arnetz, J.E.; Goetz, C.M.; Sudan, S.; Arble, E.; Janisse, J.; Arnetz, B.B. Personal Protective Equipment and Mental Health Symptoms Among Nurses During the COVID-19 Pandemic. J. Occup. Environ. Med. 2020, 62, 892-897. [CrossRef] [PubMed]

15. Ramírez, L.P.G.; Arriaga, R.J.M.; Hernández-Gonzalez, M.A.; De la Roca-Chiapas, J.M. Psychological Distress and Signs of Post-Traumatic Stress in Response to the COVID-19 Health Emergency in a Mexican Sample. Psychol. Res. Behav. Manag. 2020, 13, 589-597. [CrossRef] [PubMed]

16. Chew, N.W.; Ngiam, J.N.; Tan, B.Y.Q.; Tham, S.M.; Tan, C.Y.; Jing, M.; Sagayanathan, R.; Chen, J.T.; Wong, L.Y.H.; Ahmad, A.; et al. Asian-Pacific perspective on the psychological well-being of healthcare workers during the evolution of the COVID-19 pandemic. BJPsych. Open 2020, 6, e116. [CrossRef] [PubMed]

17. Tan, B.Y.Q.; Chew, N.W.S.; Lee, G.K.H.; Jing, M.; Goh, Y.; Yeo, L.L.L.; Zhang, K.; Chin, H.K.; Ahmad, A.; Khan, F.A.; et al. Psychological impact of the COVID-19 pandemic on health care workers in Singapore. Ann. Intern. Med. 2020, 173, 317-320. [CrossRef]

18. Khasne, R.W.; Dhakulkar, B.S.; Mahajan, H.C.; Kulkarni, A.P. Burnout among Healthcare Workers during COVID-19 Pandemic in India: Results of a Questionnaire-based Survey. Indian J. Crit. Care Med. 2020, 24, 664-671. [CrossRef]

19. Song, X.; Fu, W.; Liu, X.; Luo, Z.; Wang, R.; Zhou, N.; Yan, S.; Lv, C. Mental health status of medical staff in emergency departments during the Coronavirus disease 2019 epidemic in China. Brain Behav. Immun. 2020, 88, 60-65. [CrossRef]

20. Wang, Y.X.; Guo, H.T.; Du, X.W.; Song, W.; Lu, C.; Hao, W.N. Factors associated with post-traumatic stress disorder of nurses exposed to corona virus disease 2019 in China. Medicine 2020, 99, e20965. [CrossRef]

21. Si, M.; Su, X.; Jiang, Y.; Wang, W.; Gu, X.F.; Ma, L.; Li, J.; Zhang, S.K.; Ren, Z.F.; Ren, R.; et al. Psychological impact of COVID-19 on medical care workers in China. Infect. Dis. Poverty 2020, 9, 113. [CrossRef]

22. Wang, Y.; Ma, S.; Yang, C.; Cai, Z.; Hu, S.; Zhang, B.; Tang, S.; Bai, H.; Guo, X.; Wu, J.; et al. Acute psychological effects of Coronavirus Disease 2019 outbreak among healthcare workers in China: A cross-sectional study. Transl. Psychiatry 2020, 13, 348. [CrossRef]

23. Asaoka, H.; Koido, Y.; Kawashima, Y.; Ikeda, M.; Miyamoto, Y.; Nishi, D. Post-traumatic stress symptoms among medical rescue workers exposed to COVID-19 in Japan. Psychiatry Clin. Neurosci. 2020, 74, 503-505. [CrossRef]

24. Vagni, M.; Maiorano, T.; Giostra, V.; Pajardi, D. Coping With COVID-19: Emergency Stress, Secondary Trauma and Self-Efficacy in Healthcare and Emergency Workers in Italy. Front. Psychol. 2020, 11, 566912. [CrossRef] [PubMed]

25. Rossi, R.; Socci, V.; Pacitti, F.; Di Lorenzo, G.; Di Marco, A.; Siracusano, A.; Rossi, A. Mental Health Outcomes Among Frontline and Second-Line Health Care Workers During the Coronavirus Disease 2019 (COVID-19) Pandemic in Italy. JAMA Netw. Open 2020, 3, e2010185. [CrossRef]

26. González-Sanguino, C.; Ausín, B.; Ángel Castellanos, M.; Saiz, J.; López-Gómez, A.; Ugidos, C.; Muñoz, M. Mental health consequences during the initial stage of the 2020 Coronavirus pandemic (COVID-19) in Spain. Brain Behav. Immun. 2020, 87, 172-176. [CrossRef]

27. Luceño-Moreno, L.; Talavera-Velasco, B.; García-Albuerne, Y.; Martín-García, J. Symptoms of posttraumatic stress, anxiety, depression, levels of resilience and burnout in spanish health personnel during the COVID-19 Pandemic. Int. J. Environ. Res. Public Health 2020, 17, 5514. [CrossRef] [PubMed]

28. Caillet, A.; Coste, C.; Sanchez, R.; Allaouchiche, B. Psychological Impact of COVID-19 on ICU Caregivers. Anaesth. Crit. Care Pain Med. 2020, 39, 717-722. [CrossRef] [PubMed]

29. Nowicki, G.J.; Ślusarska, B.; Tucholska, K.; Naylor, K.; Chrzan-Rodak, A.; Niedorys, B. The Severity of Traumatic Stress Associated with COVID-19 Pandemic, Perception of Support, Sense of Security, and Sense of Meaning in Life among Nurses: Research Protocol and Preliminary Results from Poland. Int. J. Environ. Res. Public Health 2020, 17, 6491. [CrossRef] [PubMed]

30. d'Ettorre, G.; Pellicani, V.; Ceccarelli, G. Post-traumatic stress disorder symptoms in healthcare workers: A ten-year systematic review. Acta Biomed. Health Prof. 2020, 91, e2020009. [CrossRef]

31. Haro, J.M.; Palacin, C.; Vilagut, G.; Martínez, M.; Bernal, M.; Luque, I.; Codony, M.; Dolz, M.; Alonso, J.; Grupo ESEMeD-España. Prevalence of mental disorders and associated factors: Results from the ESEMeD-Spain study. Med. Clin. 2006, 126, 445. [CrossRef]

32. Neitzke, A.B. An illness of power: Sex and the social causes of depression. Cult. Med. Psychiatry 2016, 40, 59-73. [CrossRef]

33. Bruine de Bruin, W. Age differences in COVID-19 risk perceptions and mental health: Evidence from a national U.S. survey conducted in March 2020. J. Gerontol. B Psychol. Sci. Soc. Sci. 2020. [CrossRef]

34. Löwe, B.; Wahl, I.; Rose, M.; Spitzer, C.; Glaesmer, H.; Wingenfeld, K.; Schneider, A.; Brähler, E. A 4-item measure of depression and anxiety: Validation and standardization of the Patient Health Questionnaire-4 (PHQ-4) in the general population. J. Affect. Disord. 2010, 122, 86-95. [CrossRef] [PubMed]

35. Bambi, S.; Iozzo, P.; Lucchini, A. New issues in nursing management during the COVID-19 pandemic in Italy. Am. J. Crit. Care 2020, 122, 86-95. [CrossRef] [PubMed] 
36. Salvagioni, D.A.J.; Melanda, F.N.; Mesas, A.E.; González, A.D.; Gabani, F.L.; Andrade, S.M. Physical, psychological and occupational consequences of job burnout: A systematic review of prospective studies. PLoS ONE 2017, 12, e0185781. [CrossRef] [PubMed]

37. Adriaenssens, J.; De Gucht, V.; Maes, S. The impact of traumatic events on emergency room nurses: Findings from a questionnaire survey. Int. J. Nurs. Stud. 2012, 49, 1411-1422. [CrossRef] [PubMed]

38. Somville, F.J.; De Gucht, V.; Maes, S. The impact of occupational hazards and traumatic events among Belgian emergency physicians. Scand. J. Trauma Resusc. Emerg. Med. 2016, 24, 59. [CrossRef]

39. Giorgi, G.; Lecca, L.I.; Alessio, F.; Finstad, G.L.; Bondanini, G.; Lulli, L.G.; Arcangeli, G.; Mucci, N. COVID-19-Related Mental Health Effects in the Workplace: A Narrative Review. Int. J. Environ. Res. Public Health 2020, 17, 7857. [CrossRef]

40. Guay, S.; Beaulieu-Prévost, D.; Sader, J.; Marchand, A. A systematic literature review of early posttraumatic interventions for victims of violent crime. Aggress. Violent Behav. 2019, 46, 15-24. [CrossRef]

41. Cao, J.; Wei, J.; Zhu, H.; Duan, Y.; Geng, W.; Hong, X.; Jiang, J.; Zhao, X.; Zhu, B. A study of basic needs and psychological wellbeing of medical workers in the fever clinic of a tertiary general hospital in Beijing during the COVID-19 outbreak. Psychother. Psychosom. 2020, 89, 252-254. [CrossRef]

42. Theorell, T. COVID-19 and Working Conditions in Health Care. Psychother. Psychosom. 2020, 89, 193-194. [CrossRef]

43. Pan, A.; Liu, L.; Wang, C.; Guo, H.; Hao, X.; Wang, Q.; Huang, J.; He, N.; Yu, H.; Lin, X.; et al. Association of public health interventions with the epidemiology of the COVID-19 outbreak in Wuhan, China. JAMA 2020, 323, 1915-1923. [CrossRef]

44. Thibodeau, M.A.; Welch, P.G.; Sareen, J.; Asmundson, G.J.G. Anxiety disorders are independently associated with suicide ideation and attempts: Propensity score matching in two epidemiological samples. Depress. Anxiety 2013, 30, 947-954. [CrossRef] [PubMed]

45. Dutheil, F.; Aubert, C.; Pereira, B.; Dambrun, M.; Moustafa, F.; Mermillod, M.; Baker, J.S.; Trousselard, M.; Lesage, F.X.; Navel, V. Suicide among physicians and health-care workers: A systematic review and meta-analysis. PLoS ONE 2019, 14, e0226361. [CrossRef] [PubMed]

46. Fuhr, D.C.; Acarturk, C.; McGrath, M.; Ilkkursun, Z.; Sondorp, E.; Sijbrandij, M.; Ventevogel, P.; Cuijpers, P.; McKee, M.; Roberts, B. Treatment gap and mental health service use among Syrian refugees in Sultanbeyli, Istanbul: A cross-sectional survey. Epidemiol. Psychiatr. Sci. 2019, 29, e70. [CrossRef] [PubMed]

47. Giovanetti, M.; Benedetti, F.; Campisi, G.; Ciccozzi, A.; Fabris, S.; Ceccarelli, G.; Tambone, V.; Caruso, A.; Angeletti, S.; Zella, D.; et al. Evolution patterns of SARS-CoV-2: Snapshot on its genome variants. Biochem. Biophys. Res. Commun. 2020. [CrossRef]

48. Russo, A.; Bellelli, V.; Ceccarelli, G.; Marincola Cattaneo, F.; Bianchi, L.; Pierro, R.; Russo, R.; Steffanina, A.; Pugliese, F.; Mastroianni, C.M.; et al. Comparison Between Hospitalized Patients Affected or Not Affected by Coronavirus Disease 2019. Clin. Infect. Dis. 2020, ciaa1745. [CrossRef]

49. d'Ettorre, G.; Ceccarelli, G.; Marazzato, M.; Campagna, G.; Pinacchio, C.; Alessandri, F.; Ruberto, F.; Rossi, G.; Celani, L.; Scagnolari, C. Challenges in the Management of SARS-CoV2 Infection: The Role of Oral Bacteriotherapy as Complementary Therapeutic Strategy to Avoid the Progression of COVID-19. Front. Med. (Lausanne) 2020, 7, 389. [CrossRef]

50. Violi, F.; Cangemi, R.; Romiti, G.F.; Ceccarelli, G.; Oliva, A.; Alessandri, F.; Pirro, M.; Pignatelli, P.; Lichtner, M.; Carraro, A.; et al. Is Albumin Predictor of Mortality in COVID-19? Antioxid Redox Signal. 2020. [CrossRef]

51. Violi, F.; Ceccarelli, G.; Cangemi, R.; Alessandri, F.; D’Ettorre, G.; Oliva, A.; Pastori, D.; Loffredo, L.; Pignatelli, P.; Ruberto, F. Hypoalbuminemia, Coagulopathy, and Vascular Disease in COVID-19. Circ. Res. 2020, 127, 400-401. [CrossRef]

52. Ceccarelli, G.; Alessandri, F.; d’Ettorre, G.; Borrazzo, C.; Spagnolello, O.; Oliva, A.; Ruberto, F.; Mastroianni, C.M.; Pugliese, F.; Venditti, M.; et al. Is teicoplanin a complementary treatment option for COVID-19? The question remains. Int. J. Antimicrob. Agents 2020, 56, 106029. [CrossRef] 